\title{
A ANÁLISE PSICOLÓGICA DE TUMULTOS, BOATOS E GREVES RICHARD KANNER
}

"E melhor escorregar com o pé do que com a lingua. - Krates dE TEBAS

O tema acima apontado costuma ser analisado e estudado nos mais variados prismas; dentre êles o político, o social e o econômico são os mais freqüientes. Dificilmente encontramos uma focalização psicológica que leve em consideração a đinâmica profunda dêsses fenômenos; as raras observações que temos estão contidas em alguns livros de Psicologia Industrial e geralmente só apontam o fato e os elementos mais concretos e superficiais.

O nosso trabalho pretende coordenar episódios reais com os dados que a Psiquiatria moderna e especialmente a Psicanálise nos proporcionam, possibilitando, assim, uma visão mais profunda do assunto.

Lembremo-nos de que a posição do médico de hoje não pode ser comparada à que êle ainda tinha há um século. Sua situação era a do homem que se propunha curar doenças - portanto, a relação era pràticamente de indivíduo para indivíduo. $\mathrm{Na}$ medida em que êle adquiria elementos mais básicos sôbre o tratamento das moléstias,

Richard Kanner - Professor (contratado) de Psicologia, do Departamento de Ciências Sociais, da Escola de Administração de Emprêsas de São Paulo, e Diretor-Superintendente do IATROS - Instituto de Medicina. 
crescia sua capacidade de evitá-las e aumentava sua responsabilidade social (higiene pública, serviços de profilaxia etc.). Lembremo-nos também de que, em relação ao psiquiatra ou ao psicólogo, o mesmo fenômeno se verifica. Não vão longe os tempos em que êsses profissionais só podiam tomar medidas atenuantes em relação à moléstia mental, pois os seus componentes reais pouco eram compreendidos ou aceitos. Hoje em dia estamos armados com maior entendimento e a aplicação dos conceitos de FREUD, JUNG, MELANIE KLEIN e outros nos tratamentos psicológicos individuais ou grupais dão resultado amplamente satisfatório e, também, a responsabilidade de tornar públicos os conhecimentos obtidos, não sendo mais admissíve! que dados de tão grande importância e de alto significado coletivo fiquem confinados aos consultórios de alguns especialistas.

Justifica-se ainda êste trabalho pela seguinte razão: especialmente em relação às greves, costumam ser levados em consideração fatôres políticos, econômicos ou sociais . Êsses aspectos não se desqualificam; muitas vêzes, porém, êles têm servido para encobrir a motivação psicológica. Ora, sabemos que o ser humano tem tendência a apresentar como justificativa para a sua conduta causas èticamente aceitáveis . Assim, guerras, revoluções e destruições são sempre levadas a cabo em nome da "dignidade", da "preservação de valôres" etc. e nunca em nome da cobiça, do ódio e da inveja.

A capacidade do indivíduo e da coletividade de se enganarem leva o homem a considerar, quase sempre, os fatos do mundo externo, ficando ocultas as causas que dizem respeito à vida psíquica .

Depois de dar as razões dêste estudo, cabe-nos alinhar as premissas em que se assenta:

- existem motivos inconscientes para a detonação de tumultos, greves ou boatos;

- há necessidade de atendimento e tratamento dêsses episódios, que levem em consideração o aspecto psicológico; 
a eclosão dêsses fenômenos fica facilitada porque o grupo humano permite ao indivíduo atitudes que êle isoladamente não adotaria.

Para maior facilidade abordaremos cada um dos pontos separadamente e, em seguida, faremos uma síntese final.

\section{TUMULTOS}

Têm sido relatados casos nos quais se estabelecem tumultos porque alguém dá um grito de advertência ou perigo. Nessa situação é comum que o público em pânico se destroce na ânsia de escapar, sem ao menos ter verificado objetivamente se havia gravidade mesmo. Trata-se, portanto, de uma situação patológica - compreensível, sim, mas nem por isso menos perniciosa. Aliás, devemos assinalar que, muitas vêzes, em tais ocorrências, a atitude firme e determinada de um homem é capaz de modificar a corrente dos acontecimentos, prevenindo tragédias de grande extensão.

Podemos, portanto, deduzir que o tumulto é uma reação infantil, imatura sob o aspecto emocional, onde a imaginação catastrófica toma conta do indivíduo e da coletividade, exigindo um líder que não se deixe contaminar pelo sentimento de temor persecutório já estabelecido, tomando medidas que reconduzam os indivíduos a um contato com as reais medidas que devam ser tomadas.

Em outras palavras podemos dizer que um grupo que descamba para uma situação de tumulto perdeu o contato com a realidade exterior para atender exclusivamente a imposições de um mundo interior aterrorizado e incoerentes; a "chamada de volta" ocorre quando o grupo retoma o contato com a realidade externa pela intervenção de uma ou várias pessoas que posteriormente se tornam líderes, caso não o sejam já anteriormente; ela pode também ocorrer por fôrça de um acontecimento imprevisto e de efeito calmante.

Lembramo-nos, a propósito, do relato que um psiquiatra norte-americano faz a respeito de uma de suas experiên- 
cias no fim da Segunda Grande Guerra.$^{1}$ Conta-nos êle que, fazendo parte das tropas que ocuparam um campo de concentração alemão, sentiu-se tomado por intenso sentimento de compaixão por aquêles sêres humanos que estavam nas indescritiveis condições de miséria física e espiritual que todos já ouvimos descritas ou conhecemos por fotografias. Tinha sido êle designado pelo seu comandante para falar aos prisioneiros, prometendo-lhes o auxílio das tropas de ocupação, mas apelando para que tivessem um pouco de paciência, pois haveria uma pequena demora na chegada do auxílio. Êle fêz o apêlo sentindo-se, durante tôda a exposição àquela coletividade desesperada, dominado pelo sentimento de compaixão.

A reação do grupo foi inesperada, pois, em vez do alívio que êle supunha fôsse decorrer da nova situação, o que se verificou foi uma crescente onda de protestos, acompanhada de atitudes ameaçadoras que começaram a ser tomadas contra o orador. Êle sentiu, então, mêdo de um tumulto que poderia surgir, do qual resultariam agressões contra êle. Dominado agora por êste sentimento que substituía o anterior, gritou aos seus ouvintes que, caso persistissem na sua atitude, teriam de contar com a possibilidade de uma suspensão do auxílio por tempo indeterminado. Isso fêz com que êles se acalmassem.

Analisando o fenômeno, êle chegou à conclusão de que fôra inadequada a sua primeira conduta diante daquele grupo que, por fôrça das circunstâncias extremamente persecutórias que tivera de suportar, só podia estar desconfiado, agressivo e, portanto, com mêdo das suas próprias reações. O grupo sentiu nêle um líder fraco e obrigou-o, com suas ameaças, a mudar a atitude para uma liderança de tipo despótico, absolutista, primitivo, mas adequado à própria primitividade emocional do grupo. Ele atendeu ao pedido inconsciente daqueles homens de conduzi-los à realidade, à fôrça, por assim dizer, pois êles mesmos não se sentiam capazes disso. Há outros fatôres

1) Orto E. SPerling, Psychoamalysis and Social Sciences, Nova Iorque: International Universities Presses, Inc., vol. IV, 1955. 
que analisar nesse episódio, mas, para resumir, poderíamos dizer que êle se compara ao de uma criança que, agitada e dominada pelo pânico, pede secretamente a intervenção enérgica da autoridade paterna para se sentir em segurança diante dos seus próprios impulsos.

Em sintese, vemos que o tumulto se estabelece nas seguintes condições:

a) existência de uma coletividade de nivel emocional rudimentar;

b) incidência de um acontecimento imprevisto ou de tipo ameaçador;

c) ausência de elementos que permitam ao grupo avaliar as possibilidades de defesa.

Se são aceitas como válidas as premissas por nós colocadas, podemos chegar às seguintes conclusões: $1 .^{a}$ ) além de manter uma constante ação educacional para fazer o grupo enfrentar situações difíceis com maturidade, a chefia deve manter-se em constante contato com êle para mantê-lo precisamente informado; e $2 .^{a}$ ) a própria chefia deve estar capacitada, emocional e intelectualmente, a dar soluções as mais satisfatórias em ocasiões problemáticas.

Em nossa opinião, quando há preenchimento dêsses quesitos dificilmente se estabelece tumulto, pois tôdas as circunstâncias de manejo das condições externas foram proporcionadas. Mesmo que um ou outro indivíduo possa cair em pânico, êle não encontrará as condições de contaminação necessárias. Aliás, é por isso que os tumultos podem ser fàcilmente desencadeados em ocasiões de ausência de chefia e de mau conhecimento da realidade das situações.

BOATOS

Outro fenômeno psicopatológico coletivo e que tem certo parentesco com o anterior é o do boato. Aqui, também, o mau conhecimento da realidade, a imaturidade do gru- 
po e a emoção persecutória ocupam lugar de importância na estruturação do fenômeno. No entanto, êle tem certas caraterísticas específicas que precisamos conhecer.

Comecemos com um exemplo citado por CARL GuSTAv JUNG $^{2}$ no seu trabalho Psicologia do Rumor, que tem como tema central o episódio ocorrido entre um professor e uma classe de doze ou treze meninas adolescentes. Corria o boato de que êsse professor teria tido um relacionamento íntimo com uma das alunas. O professor indignado, averiguando a origem do boato, descobriu que a sua fonte era a própria aluna com a qual teria havido a pretensa relação sexual. Êle quis tomar uma atitude punitiva; deu-se, então, a intervenção do eminente psiquiatra supracitado, que pediu fôsse suspensa a punição até o esclarecimento do assunto.

Com grande surprêsa JuNG verificou o seguinte: a aluna contara a uma colega que havia sonhado com o professor: fizera uma viagem de navio com êle, tendo, à noite, pernoitado numa granja, onde, por falta de espaço, rapazes e môças dormiriam no mesmo quarto; e a espôsa do dono da granja dera à luz uma criança naquela mesma noite.

O conteúdo sexual inconsciente dêsse sonho é evidente; êle foi apanhado pela colega, embora de maneira pouco definida. Ao contar o sonho a uma terceira colega, ela acrescentou que o professor teria tomado a primeira em seus braços. Em determinado momento das transmissões entre as colegas, uma omitiu que se tratava de sonho. Assim, de deformação em deformação, cristalizou-se a versão que chegou aos ouvidos do professor .

Vemos, desde logo, que aquêle boato correspondeu a uma necessidade da classe de formar uma situação em que seria testada a receptividade que o professor daria aos secretos anseios românticos de suas alunas. A resposta dêste foi tão incisiva que há de suspeitar que também êle, inconscientemente, percebeu o que estava em jôgo e quis, através da punição da aluna, definir de uma vez por tôdas a situa-

2) C. G. JUng, Psychologie und Erziehung, Zurique, Roscher Verlag. 
ção. Não nos cabe apontar o êrro da sua atuação nesse episódio e, sim, reconhecer-lhe o mérito de ter contribuído para um esclarecimento extremamente precioso do tema em foco.

$O$ resultado dêsse estudo mostrou que no boato há um desejo secreto que está requerendo esclarecimento. No caso citado um grupo de adolescentes queria saber até que ponto seriam toleradas suas aspirações amorosas em relação ao professor, e poderíamos mesmo dizer que, de certa maneira, o seu propósito foi atendido: elas souberam que com êsse professor não seria aconselhável o namôro. Se houve frustração, houve, pelo menos, informação .

No levantamento feito por JUNG do caso o que mais impressiona é a forma pela qual cada aluna se encarregou de contribuir com o seu tijolo para a construção dêsse edifício, cuja arquitetura visava a atender uma básica necessidade humana, isto é, a de saber "a quantas ando e o que é que o outro pensa disto".

Poderia aqui surgir uma pergunta aparentemente embaraçosa: que dizer dos boatos e rumôres cujo conteúdo é evidentemente desagradável para quem o cria e para quem $\mathrm{c}$ propaga? No caso anterior tôdas as consequiências desastrosas de uma possível veracidade do boato recairiam sôbre o professor, e as alunas poderiam usufruir o sabor de se verem centro de atenções, tendo ainda por saldo as vantagens que já apontamos. Tal não se dá no exempio seguinte.

Há algum tempo os jornais anunciaram, em manchetes ostensivas, que o primeiro-ministro da União Soviética declarara a jornalistas que êsse país estaria de posse de uma terrível arma que, se empregada, poderia extinguir a vida sôbre a face da terra. Os jornais que trouxeram essa notícia não podem ser tidos como favoráveis à política seguida pela URSS e, portanto, o anúncio não pode ser considerado como vindo de alguém que tivesse interêsse em atribuir tal poderio ao citado país. A notícia foi confirmada, desmentida, parcialmente reafirmada, corrigida etc. $\epsilon$ adquiriu as caraterísticas de rumor ao qual faltam bases 
concretas. A pergunta que se coloca é esta: como podem certos círculos ter interêsse em veicular um boato que, confirmado, representaria um fato oneroso para êsses mesmos círculos?

Para responder a essa pergunta precisamos recorrer a determinados conhecimentos de Psicodinâmica que nos ajudam a compreender êsse paradoxo. Sabemos hoje que um indivíduo pode ter o maior interêsse em crer em determinada situação, mesmo que ela represente um pesado prejuizo para êle, porque isso lhe permite atribuir a outro uma série de maldades, enquanto êle fica sendo a vítima inocente dêsse estado de coisas. Assim, pode o indivíduo atribuir a um colega de trabalho interêsse em roubar-lhe - lugar, podendo chegar a fazer votos íntimos de que tal seja verdade, porque assim ficaria livre do perigo de ter de perceber que é êle que está interessado em usurpar o lugar do outro. Êsse mecanismo é uma defesa que a pessoa emprega para negar certas verdades interiores, usando o próximo para essa negação. Êsse processo, que chamamos projeção, é inteiramente inconsciente, e o indivíduo, crendo piamente na situação, pode sentir-se honestamente perseguido e passar a atuar em função disso.

No caso da superarma soviética, poderíamos dizer que a notícia, embora objetivamente má para quem a propala, terá todo o crédito, pois coloca o adversário numa situação de maldoso diante do qual se deve tomar muito cuidado. Êsse processo permite, pois, repetindo, a negação da própria agressividade, além de pôr em mobilização as defesas. Nesse sentido podem também ser entendidos determinados boatos que circulam entre patrões e empregados, nos quais uns e outros se atribuem mùtuamente uma série de ciladas ou de más intenções que os deixam apreensivos e, ao mesmo tempo, os aliviam no sentido de que cada um pode "enxergar o diabo" no outro.

Queremos deixar claro que não é nossa intenção atribuir culpas a quem quer que seja. Aliás, outra não pode ser a atitude de quem se propõe a estudar cientìficamente um assunto. É preciso, isto sim, ter sincero interêsse em com- 
preender e fazer compreender. Acreditamos que, se conseguirmos isso, muitos mal-entendidos poderão ser evitados, em benefício da convivência harmoniosa e da produtividade.

Permitimo-nos, ainda a êsse respeito, citar um exemplo típico, ocorrido entre o autor e um cliente que certo dia veio, alvoroçadamente, perguntar se era verdade que o preço da consulta iria, de um mês para outro, ser $100 \%$ aumentado. Êsse paciente, aliás, estava fazendo um trabatho psicoterápico de regular intensidade e, a ser verdade aquilo que êle ouvira dizer, não teria recursos para continuar o tratamento. Imediatamente tivemos a sensação de que havia alguma coisa oculta atrás dêsse boato e aguardamos o que o paciente teria a nos comunicar ainda. Depois de alguns instantes de silêncio o cliente disse mais ou menos o seguinte: "eu queria avisar que êste mês, por fôrça de circunstâncias imprevistas, não poderei pagar, de modo que o senhor terá de aguardar até o próximo, quando então saldarei os dois meses conjuntamente".

Nesse ponto pudemos mostrar-lhe a arbitrariedade que cometia, pois nos comunicava o fato em vez de nos pedir licença. A situação fôra por êle concebida inconscientemente, e a defesa que imediatamente tomara fôra de atribuir-nos um preço extorsivo. O paciente preferiu, portanto, apegar-se a uma idéia que era para êle altamente desfavorável na realidade, mas com a vantagem secreta de atribuir a outro a maldade que não quis admitir. em si .

Outro tipo de boato é aquêle em que determinado grupo se sente culpado por alguma ação danosa e começa a ter mêdo de alguma represália por parte do prejudicado. Quem de nós não tem lembrança de algum professor em relação ao qual nossa classe agia desrespeitosamente, mas que começava a suspeitar que seria vítima de terrivel vingança nos exames finais? Sentia-se no ar o sorriso mefistofélico do professor, e qualquer gesto menos comum da parte dêle era interpretado como inequívoco sinal de que o dia de acêrto de contas se aproximava. Aqui se percebe que a classe, culpada como se sente, está como que 
pedindo um castigo. Mas, uma vez que também o teme, adota uma solução de compromisso que consiste em ficar a afligir-se com desgraças que nada têm de real.

Outro tipo de boato, ainda, é aquêle que é gratificador para a outra parte. Assim corre, por exemplo, o rumor de que uma artista muito querida vai casar-se com um homem de alto gabarito cultural, econômico, social etc. Trata-se de uma situação em que se deseja que algo de bom aconteça para a pessoa querida e êsse rumor dá satisfação ao citado anseio.

Nos exemplos que relatamos o primeiro e o segundo casos representam boatos do tipo paranóico; o terceiro caso é exemplo claro de sentimento de culpa de tipo persecutório; o quarto tem as caraterísticas de um boato em que o amor, a benevolência e a proteção (numa atitude reparadora) são os móveis básicos.

Parece-nos que fica bem claro que o boato tem motivações precisas que podem ser entendidas corn algum esfôrço. A importância dêsse fato abordaremos no final do nosso trabalho.

\section{GREVES}

A nosso ver, tem-se atribuído muito menos importância ao comportamento psicológico na greve do que seria de esperar. Para esclarecer melhor o que queremos dizer vamo-nos valer da experiência que temos adquirido em relações a êsse assunto em Psicoterapia, especialmente na Psicoterapia de Grupo (isto é, no tratamento feito em grupos, por meio de recursos psicológicos, esportivos, teatrais etc.), em que a greve de indivíduos ou então de grupos inteiros aparece de forma bem marcante.

Que greves são essas? Temos a greve do silêncio, do não comparecimento, da falta de pagamento, do oposicionismo constante etc. Quando analisamos essas ocorrências percebemos que geralmente são atitudes de protesto, sob as quais se percebe claramente que a pessoa (ou grupo) 
acredita firmemente que está sendo lograda no sentido de não receber aquilo que poderia receber do psicoterapeuta ou então aquilo a que faria jus. Por exemplo: em determinado grupo que inicia o tratamento, um cliente aparece com uma situação bastante penosa que, na opinião do grupo, requer imediato atendimento. Conclui-se que o psicoterapeuta deveria intervir na chefia do lugar onde êsse cliente trabalha para a obtenção daquilo que o paciente acha atenuará o problema que enfrenta.

Não entramos nos pormenores da situação por serem desnecessários e porque alongariam demais a nossa exposição. Apenas podemos dizer que a solução aventada era, a nosso ver, inútil e, além disso, tècnicamente falando, contra-indicada. No manejo dêsse episódio, porém, quando o grupo percebeu que não seria tomada a atitude por êle desejada, começou a haver greve, isto é, a haver faltas, perda de elementos e comentários constantes sôbre a nossa inépcia.

Acreditamos que não erramos quando dizemos que êsse grupo estava fazendo uma idéia completamente idealizada do psicoterapeuta, simplesmente não podendo aceitar que tínhamos limites, além de outras fantasias.

Isso lembra de perto a criança que também não enxerga a realidade. Observamos com freqüência que qualquer tentativa dos pais no sentido de mostrar ao filho os limites dêste ou os próprios esbarra num violento protesto, pois o educando sente o fato mais ou menos assim: "Querem me limitar, não é? Pois não deixarei". Sòmente quando êle percebe, em experiências geralmente bem dolorosas, que na limitação não há antagonismos ou desaforos é que se conforma com aceitar e até colaborar na limitação.

Da mesma forma, só o progressivo amadurecimento emocional do cliente pode levá-lo a aceitar que o terapeuta tem podêres limitados e que, por amor ao tratamento, não pode ceder à exigência de superproteção por parte do cliente, e que êste precisa usar os seus próprios recursos em seu benefício; então êle aprende a pedir, a reivindicar 
mesmo, mas através de meios não destrutivos para êle ou para outros. Por outro lado, mesmo que fôsse possível atender o desejo do cliente, êste não deveria estar apoiando sua exigência em chantagem autodestrutiva, tal como a criança que embirra quando não obtém o que quer. A semelhança dêsse fato com o que se passa - tanto com patrões, quanto com funcionários - quando há conflito trabalhista é fácil perceber. Os leitores já devem ter notado que, muitas vêzes, numa situação dessas cada uma das partes toma uma atitude rígida de exigência na suposição de que o outro lado poderia dar-lhe isto ou aquilo, e que, se não o faz, é por pura maldade.

Porém, mesmo quando, por demonstração da realidade dos fatos, consegue-se mostrar que não há possibilidade de atendimento ou, então, só em parte será possível atender o pedido, entra o "prestígio". Uma vez que nem o sindicato nem a chefia da emprêsa quer reconhecer que atuou com infantilidade, ficam regateando em tôrno de questões de somenos importância para "não dar o braço a torcer". $O$ assunto fica, às vêzes, até engraçado e a gente ri muito se o desperdício energético, a ameaça física à pessoa e as perdas materiais não fôssem sérios demais para serem encarados como anedota.

Provàvelmente, foi a percepção dessa situação que fêz com que em diversos países se criassem institutos especializados que, intervindo nos conflitos trabalhistas de maneira apaziguadora, muitas vêzes são bem aceitos pelas partes em conflito. Citamos como exemplo o Instituto " $M a x$ Planck", na Alemanha, no qual trabalha uma equipe de economistas, engenheiros, psicólogos do trabalho, advogados e outros especialistas que entra em ação no sentido de estudar o problema quando há a perspectiva de uma greve.

Uma vez que se trata de órgão completamente independente, as conclusões a que chega são as mais objetivas possíveis e geralmente são bem aceitas. Nessas ocasiões verifica-se que a exclusão dos fatôres subjetivos de sensação de ser explorado, de "prestígio" e de eliminação da ideali- 
zação da posição da outra parte removem os obstáculos para um bom entendimento.

\section{CONCLUSÕES}

O que tivemos oportunidade de expor leva-nos a uma série de considerações que precisam ser feitas.

Somos da opinião de que os conhecimentos que a atividade clínica nos dá devem ser postos à disposição dos responsáveis pela produção em nosso País, introduzindo-se definitivamente em nosso meio a prática do uso dos conhecimentos da Psicologia para evitar o aparecimento de fenômenos psicopatológicos como êsses que focalizamos.

Mais uma vez queremos lembrar o que já dissemos no iní; cio, isto é, que greves, boatos e tumultos são sintomas de doença, mesmo se considerados os seus aspectos objetivos, pois as necessidades que estão sob êsses sintomas poderiam, devidamente orientadas, encontrar soluções muito mais construtivas e adequadas.

T'al consideração nos lembra certa fase histórica que o homem atravessou nas suas tentativas de enfrentar a doença mental. Referimo-nos ao período em que a Ciência estava mergulhada no esquecimento, apesar do seu auspicioso início nos tempos hipocráticos . Nessa época, que foi denominada "da demonologia", os doentes mentais eram queimados ou torturados a fim de expulsar dêles um hipotético demônio que os estaria possuindo.

Êsse período, do qual nos lembramos com certo pudor, podia ter para si a desculpa de que os conhecimentos médicos em relação a essas doenças eram reduzidos, quase nulos. Sabe-se que é uma caraterística humana reagir com pânico, pavor e arbitrariedade diante de fenômeno cuja essência ignora. Acreditamos que não estejamos sendo pretensiosos quando dizemos que o estado atual dos conhecimentos sociológicos, psicológicos, de relaçães humanas e de administração são hoje de tal maneira adiantados que não poderemos usar diante das futuras gerações 
essa desculpa para explicar o nosso "comportamento demonológico", em face de situações como essas que estamos analisando. Seremos, isto sim, acusados de não têrmos usado aquilo que estava à nossa disposição para solucioná-las adequadamente. Mas, afinal, porque não usamos os nossos recursos nesse setor?

Cremos que o estudo objetivo de casos como êsses muitas vêzes sugere conclusões que os implicados no episódio recebem como uma espécie de censura. Aliás, enfrentamos, nesse campo, a mesma dificuldade que um psiquiatra ou um psicólogo encontra ao explicar a seu cliente determinados aspectos inconscientes da sua conduta. O paciente recebe o esclarecimento como uma crítica, especialmente quando está no início do tratamento. Com a mesma dificuldade lidam também administradores que querem introduzir novos esquemas de trabalho. Conhecem muito bem os obstáculos que surgem, menos pelas dificuldades reais de aplicação, do que pelos melindres pessoais que tais procedimentos acarretam.

Podemos imaginar que reação terá determinado diretor de emprêsa ao receber a conclusão de um estudo sôbre a greve decretada no seu ambiente de trabalho, no qual fica definido que a sua conduta inflexível ou, então, a sua ambição desmedida levou seus comandados a adotar uma atitude que poderia ter sido evitada!

O mesmo pode-se dizer de um líder sindical que, por necessidade de prestígio pessoal (por exemplo, mostrar extremo empenho na defesa de sua classe), tenha rejeitado soluções conciliatórias. Ambos, provàvelmente, a não ser que se trate de personalidades bem maduras, desculpar-se-ão com explicações que nada têm que ver com o assunto e, o que é pior, por necessidade de negação de culpa, acreditarão piamente nas suas próprias explicações.

É êsse subjetivismo que impede os meios responsáveis pelo setor do trabalho, de adotar critérios racionais e condizentes com a realidade tanto externa como interna do homem na solução dos problemas analisados. 